\title{
Growth, Fruit Yield, and Ion Concentration in Tomato Genotypes after Pre- and Post-emergence Salt Treatments
}

\author{
M.C. Bolarín, F. Pérez-Alfocea, E.A. Cano, M.T. Estañ, and M. Caro \\ Centro de Edafología y Biología Aplicada del Segura, Consejo Superior de Investigaciones Cientifcas, \\ Apartado 4195, Murcia E-30080, Spain \\ Additional index words. growth stage, Lycopersicon esculentum, $\mathrm{NaCl}$ tolerance, shoot $\mathrm{Cl}, \mathrm{Na}$ and $\mathrm{K}$ ion concentrations
}

\begin{abstract}
The effects of increasing salinity on dry weight and ion concentration of shoots at various growth stages and on fruit yield in four tomato (Lycopersicon esculentum Mill.) genotypes were assessed. The salt treatments (35, 70, and 140 mм NaCl) were applied pre-emergence (seed sowing) (pre-E) and post-emergence (four-leaf stage) (post-E) and maintained during plant growth. Genotype salt tolerance, measured as shoot dry weight in response to increases in salt concentration, varied depending on plant growth stage and salt application time. When salt was applied pre-E, salt tolerance increased with plant age, whereas when applied post-E, 45-day-old plants were the most salt tolerant. Mature plants were similarly salt tolerant independent of the growth stage at which the salt treatments began. However, fruit yield of all genotypes was higher when salt was applied pre-E than post-E. Shoot dry weight decreased as shoot $\mathrm{Cl}$ and $\mathrm{Na}$ ion concentrations increased. During early growth stages, pre-E salt-treated plants had the highest $\mathrm{Cl}$-and $\mathrm{Na}^{+}$concentrations and the lowest shoot dry weights. However, at the advanced stages, shoot $\mathrm{Cl}$ - and $\mathrm{Na}^{+}$Concentrations were equal for both salt application times. These results show that the plants must adapt to salinity during a period that allows them to develop a mechanism to regulate internal $\mathrm{Cl}$ - and $\mathrm{Na}+$ concentrations and, thus, grow under high salinity.
\end{abstract}

Salt tolerance is a complex trait. Breeders developing crops tolerant to saline soils have found few traits that can be used as markers for reliably assessing salt tolerance. In theory, phenotypic markers for salt tolerance should be easy to measure and should be expressed during seed germination, at the seedling stage, or at advanced growth stages. However, the plant's response to salinity can vary with growth stage (Shannon, 1985). Some have argued that, in certain crops, selecting for salt tolerance at the early growth stages may not correlate with the crop's tolerance at later growth stages (Ashraf and McNeilly, 1988; Kingsbury and Epstein, 1984). In many salinity studies, one harvest date has been used to correlate growth with the physiological responses to salinity. The results from such studies can be misleading when genotypes, species, or salinity treatments are compared (Hunt, 1982).

Generally, salt tolerance in tomato has been evaluated only at germination (Jones, 1986), during early plant development (Guerrier, 1984), or at maturation (Bolarín et al., 1991). However, some authors have reported that the salt tolerance of young tomato plants did not correlate highly with that of mature plants (Norlyn and Epstein, 1984; Shannon et al., 1987). Furthermore, Caro et al. (1991) pointed out that the ranking of salt-tolerant tomato genotypes based on vegetative characteristics in mature plants may differ from a ranking based on fruit yield.

We report the effects of increasing salinity at pre-emergence (pre-E) and post-emergence (post-E) on growth and ion concentrations of tomato plants at several growth stages and on fruit yield and its relationship to shoot dry weight, with the objective of defining patterns of variation in the response to salinity shown by $30,45,100$, and 180-day-old plants.

Received for publication 20 Sept. 1992. Accepted for publication 6 Dec. 1992. We gratefully acknowledge J.M. Balsalobre for her review of the manuscript; M.R. Rojo, M.I. Palop, and A. Rodriguez. for their technical assistance; and the Comision Interministerial de Ciencia y Technologia for the financial support via project AGF92-0260. The cost of publishing this paper was defrayed in part by the payment of page charges. Under postal regulations, this paper therefore must be hereby marked advertisement solely to indicate this fact.

\section{Materials and Methods}

Seeds of four tomato genotypes-Pera, Muchamiel, P-73, and GC-72-were germinated, and the plants were grown under growth chamber and greenhouse conditions. Germination and early growth stages up to 45 days after sowing (DAS) were carried out in a controlled growth chamber in a silica-sand growth medium. Environmental conditions were $28 \mathrm{C}$ constant and $85 \%$ relative humidity (RH) for germination and 28/17C (day/night), $16 \mathrm{~h}$ light (245 $\mu \mathrm{mol} \cdot \mathrm{m}^{-2} \cdot \mathrm{s}^{-1}$ intensity), and $65 \% \mathrm{RH}$ for seedling development. The plants were irrigated daily with deionized water during germination and with Hoagland's solution after the first leaf appeared. At first, a half-strength Hoagland's solution (Hoagland and Arnon, 1950) was used; it was raised to full-strength 20 DAS until the end of the experiment. The salt treatments were established by adding $0,35,70$, and $140 \mathrm{~mm} \mathrm{NaCl}$ either to deionized water or to the nutrient solution. The design consisted of two complete blocks. In the first block, salt treatments were applied starting at seed sowing (pre-E) and, in the second, 20 DAS (post-E). In both cases, salt treatments continued until the end of the experiment.

Salt-treated plants were harvested destructively at 30 and 45 DAS. Each treatment was repeated three times. Dry weight (DW) and ion concentration were determined on individual shoots. Shoot DW was measured by drying the plant material $(24 \mathrm{~h}, 65 \mathrm{C})$ using forced hot air. Sodium and $\mathrm{K}$ ion concentrations were measured by an atomic absorption spectrophotometer (model 5000; Perkin-Elmer, Norwalk, Conn.) using 200-mg dried samples that were ground and digested with $4 \mathrm{ml} 2$ nitric acid : 1 perchloric acid (v/v) at $280 \mathrm{C}$ for $24 \mathrm{~h}$. Chloride concentration was determined by potentiometrically titrating the aqueous extract with $\mathrm{AgNO}_{3}$ using a Mettler titrator (model DL40GP; Greifensee, Switzerland).

From day 45 on, the experiment was carried out in an unheated plastic greenhouse. Average daily minima and maxima during the experiment were 38/18 $\pm 2 \mathrm{C}$ (day/night) and $16 \mathrm{~h}$ light (1000 $\mu \mathrm{mol} \cdot \mathrm{m}^{-2} \cdot \mathrm{s}^{-1}$ intensity at noon). Plants were drip irrigated daily using two emitters of 2 liters/h per plant, and the amount of water 
applied at each irrigation was $28 \%$ of that evaporated during the three previous days from a class A pan located outside the greenhouse (Sánchez-Blanco et al., 1991). The total amount of water applied was $217 \mathrm{~mm}$. Salt treatments were continued by adding the same $\mathrm{NaCl}$ levels $(0,35,70$, and $140 \mathrm{~mm})$ to the aqueous feed solution made up with local irrigation water. The average root-zone electrical conductivity (EC) values for the salt treatments were 1.7, 5.3, 8.0, and $14.6 \mathrm{dS} \cdot \mathrm{m}^{-1}$ respectively. Three replications from each salt treatment were harvested destructively at 100 and 180 DAS. Dry weights and ion concentrations were determined as described above. To determine total yield, fruit were harvested weekly from three replications (three plants per replicate).

The data for each genotype were analyzed separately at each growth stage and treatment time using regression analysis.

\section{Results}

Effect of $\mathrm{NaCl}$ on shoot growth. Increasing salinity significantly reduced shoot DW, which varied with salt application time and plant age; in general, the response was linear (Table 1). The decreased shoot DW in 30- and 45-day-old plants was greater when salt was applied pre-E than post-E. At pre-E, shoot DW of all genotypes decreased in the plants receiving $35 \mathrm{~mm} \mathrm{NaCl}$ relative to the controls, except for 45-day-old Muchamiel plants. When salt was applied post-E, there were no differences between the controls and the plants receiving 35 and $70 \mathrm{~mm} \mathrm{NaCl}$ treatments for most genotypes. In 100- and 180-day-old plants, the effect of increasing $\mathrm{NaCl}$ concentration on shoot DW was similar for plants receiving pre-E or post-E treatments.

Salinity effects varied with plant growth stage and salt application time. At pre-E, salt sensitivity of all genotypes, measured as shoot DW decrease vs. salt concentration increase, increased with plant age. At post-E, the highest salt tolerances in all genotypes were shown at the early growth stage. In general, salt tolerances in 180-day-old plants were higher than those in loo-day-old plants.

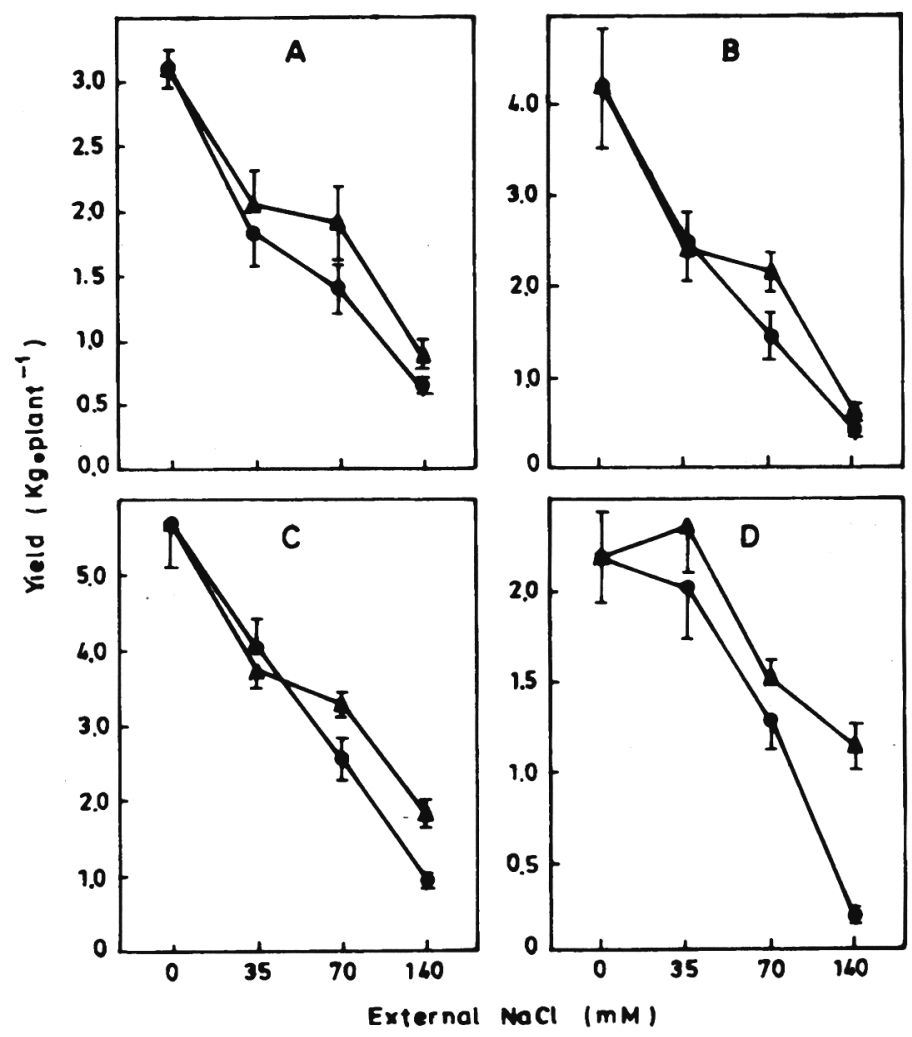

Fig. 1. Effect of $\mathrm{NaCl}$ on fruit yield of tomato genotypes (A) Pera, (B) Muchamiel, (C) P-73, and (D) GC-72. Salt treatments were applied either starting at pre-emergence $(\mathbf{A})$ or post-emergence $(\mathbf{O})$. Vertical bars represent SE.

Effect of $\mathrm{NaCl}$ on yield. Yield of all genotypes decreased as salt concentration increased; the greatest yield decreases were exhibited by P-73 and Muchamiel (Fig. 1). Yield in all genotypes

Table 1. Effect of salinity on shoot dry weight (in grams) in four tomato genotypes at several plant growth stages expressed as days after sowing (DAS). The genotypes were grown under various salt treatments applied pre- and post-emergence (pre-E and postE, respectively).

\begin{tabular}{|c|c|c|c|c|c|c|c|c|c|c|}
\hline \multirow[b]{4}{*}{ Genotype } & \multirow{4}{*}{$\begin{array}{c}\text { Growth } \\
\text { stage } \\
\text { (DAS) }\end{array}$} & & \multicolumn{6}{|c|}{ Application time } & & \\
\hline & & & \multicolumn{3}{|c|}{ Pre-E } & \multicolumn{3}{|c|}{ Post-E } & & \\
\hline & & \multicolumn{7}{|c|}{$\mathrm{NaCl}$ concn $(\mathrm{mM})$} & \multicolumn{2}{|c|}{ Significance } \\
\hline & & 0 (control) & 35 & 70 & 140 & 35 & 70 & 140 & Pre-E & Post-E \\
\hline \multicolumn{11}{|c|}{ Shoot dry wt $(g)$} \\
\hline \multirow[t]{4}{*}{ Pera } & 30 & 0.22 & 0.12 & 0.10 & 0.12 & 0.19 & 0.19 & 0.12 & $\mathrm{Q}^{* * *}$ & $\mathrm{~L}^{* * *}$ \\
\hline & 45 & 1.02 & 0.79 & 0.48 & 0.48 & 1.37 & 0.76 & 0.56 & $\mathrm{~L}^{* * *}$ & $\mathrm{~L}, \mathrm{Q}^{*}$ \\
\hline & 100 & 200 & 161 & 83 & 53 & 163 & 132 & 44 & $\mathrm{~L}^{* * *}$ & $\mathrm{~L}^{* * *}$ \\
\hline & 180 & 427 & 351 & 293 & 212 & 408 & 278 & 197 & $\mathrm{~L}^{* * *}$ & $\mathrm{~L}^{* * *}$ \\
\hline \multirow[t]{4}{*}{ Muchamiel } & 30 & 0.28 & 0.10 & 0.09 & 0.09 & 0.21 & 0.13 & 0.12 & $\mathrm{Q}^{* * *}$ & $\mathrm{~L}^{* * *}$ \\
\hline & 45 & 0.53 & 0.52 & 0.34 & 0.15 & 1.00 & 0.55 & 0.44 & $\mathbf{L}^{*}$ & NS \\
\hline & 100 & 221 & 135 & 118 & 51 & 145 & 103 & 33 & $\mathrm{~L}^{* * *}$ & $\mathrm{~L}^{* * *}$ \\
\hline & 180 & 362 & 294 & 290 & 174 & 292 & 265 & 210 & $\mathrm{~L}^{* * *}$ & $\mathrm{~L}^{* * *}$ \\
\hline \multirow[t]{4}{*}{ P-73 } & 30 & 0.27 & 0.14 & 0.07 & 0.05 & 0.18 & 0.17 & 0.13 & $\mathrm{~L}^{* * *}$ & $\mathrm{~L}, \mathrm{Q}^{* *}$ \\
\hline & 45 & 1.08 & 0.39 & 0.23 & 0.12 & 1.13 & 1.05 & 0.50 & $\mathrm{Q}^{* *}$ & $\mathrm{~L}, \mathrm{Q}^{* *}$ \\
\hline & 100 & 152 & 126 & 96 & 40 & 132 & 94 & 29 & $\mathrm{~L}^{* * *}$ & $\mathrm{~L}^{* * *}$ \\
\hline & 180 & 230 & 201 & 136 & 91 & 181 & 174 & 85 & $\mathrm{~L}^{* * *}$ & $\mathrm{~L}^{* * *}$ \\
\hline \multirow[t]{4}{*}{ GC-72 } & 30 & 0.20 & 0.12 & 0.06 & 0.04 & 0.22 & 0.18 & 0.12 & $\mathrm{Q}^{* *}$ & NS \\
\hline & 45 & 1.77 & 0.47 & 0.21 & 0.10 & 1.57 & 1.63 & 0.23 & $\mathrm{Q}^{* *}$ & $\mathrm{~L}, \mathrm{Q}^{* *}$ \\
\hline & 100 & 183 & 135 & 55 & 64 & 172 & 113 & 41 & $\mathrm{Q}^{* * *}$ & $\mathrm{~L}^{* * *}$ \\
\hline & 180 & 425 & 304 & 198 & 155 & 318 & 324 & 134 & $\mathrm{~L}, \mathrm{Q}^{* *}$ & $\mathrm{~L}^{* * *}$ \\
\hline
\end{tabular}

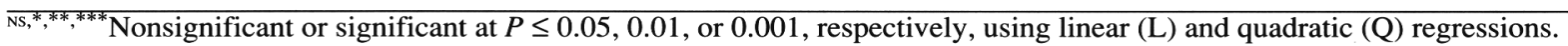



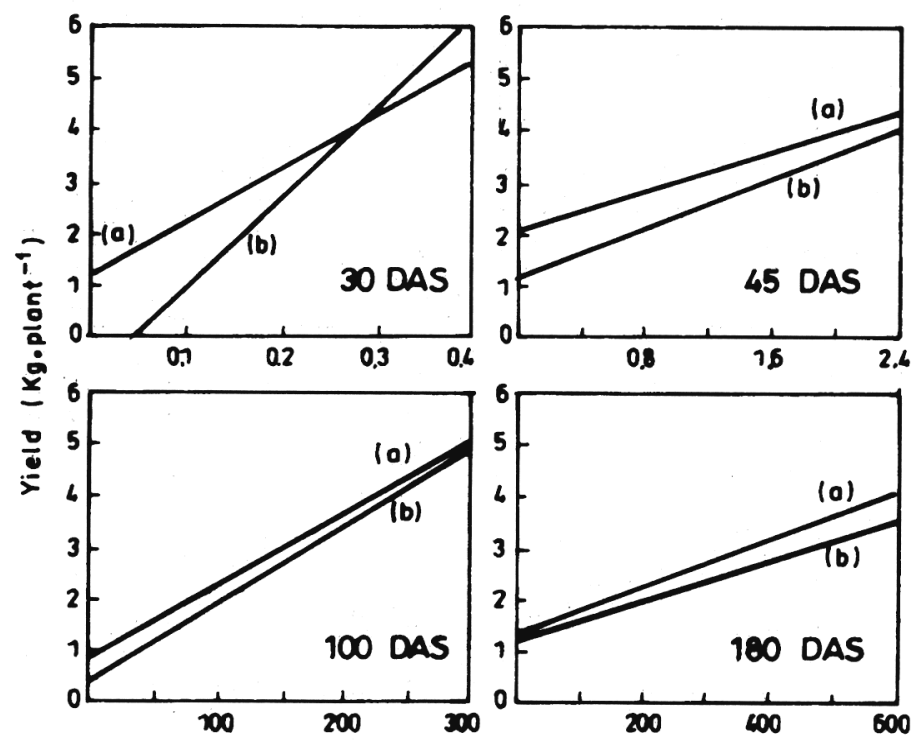

Shoot ory weight $\left(g \cdot\right.$ plont $\left.^{-1}\right)$

Fig. 2. Regressions of yield in four tomato genotypes grown at different $\mathrm{NaCl}$ concentrations on shoot dry weight of plants $30,45,100$, and 180 days after sowing (DAS). Salt treatments were applied starting at pre-emergence (a) or post-emergence (b). generally was higher when salt treatments were applied pre-E than post-E.

Relationship between yield and shoot dry weight at four growth stages. The degree of correlation between yield and shoot-DW was assessed by linear regression (Fig. 2). Yield correlated highly $(P \leq$ 0.001 ) with shoot DW in 30- and 100-day-old plants, when salt was applied either pre-E or post-E. In 45- (pre-E and post-E) and 180-day-old (post-E) plants, correlation coefficients were significant at $P \leq 0.05$, and at $P \leq 0.01$ in 180-day-old plants treated pre-E. Regression lines of yield vs. shoot DW for plants treated pre-E and post-E were significantly different only in 30- and 45-day-old seedlings. Slope and intercept were significantly different in 30-day-old seedlings, while only the intercept was significantly different in 45-day-old seedlings (Fig. 2).

Shoot $\mathrm{Cl}, \mathrm{Na}$, and $\mathrm{K}$ ion concentrations. Shoot $\mathrm{Cl}-$ and $\mathrm{Na}^{+}$ concentrations increased with salinity in all genotypes; the increases depended on salt application time (Figs. 3 and 4). As salinity increased, shoot $\mathrm{Cl}-$ and $\mathrm{Na}^{+}$concentrations in plants treated pre-E were higher in 30- and 45-day-old than in 100- and 180-day-old plants. These differences were much higher for $\mathrm{Na}^{+}$, than for $\mathrm{Cl}$ - concentration.

Shoot $\mathrm{Cl}$ - concentration in-plants treated post-E did not decrease with plant age. Unlike plants treated pre-E; the lowest $\mathrm{Cl}$ concentrations were found in 30-day-old seedlings. Variations in shoot $\mathrm{Na}^{+}$concentrations with plant age differed from those

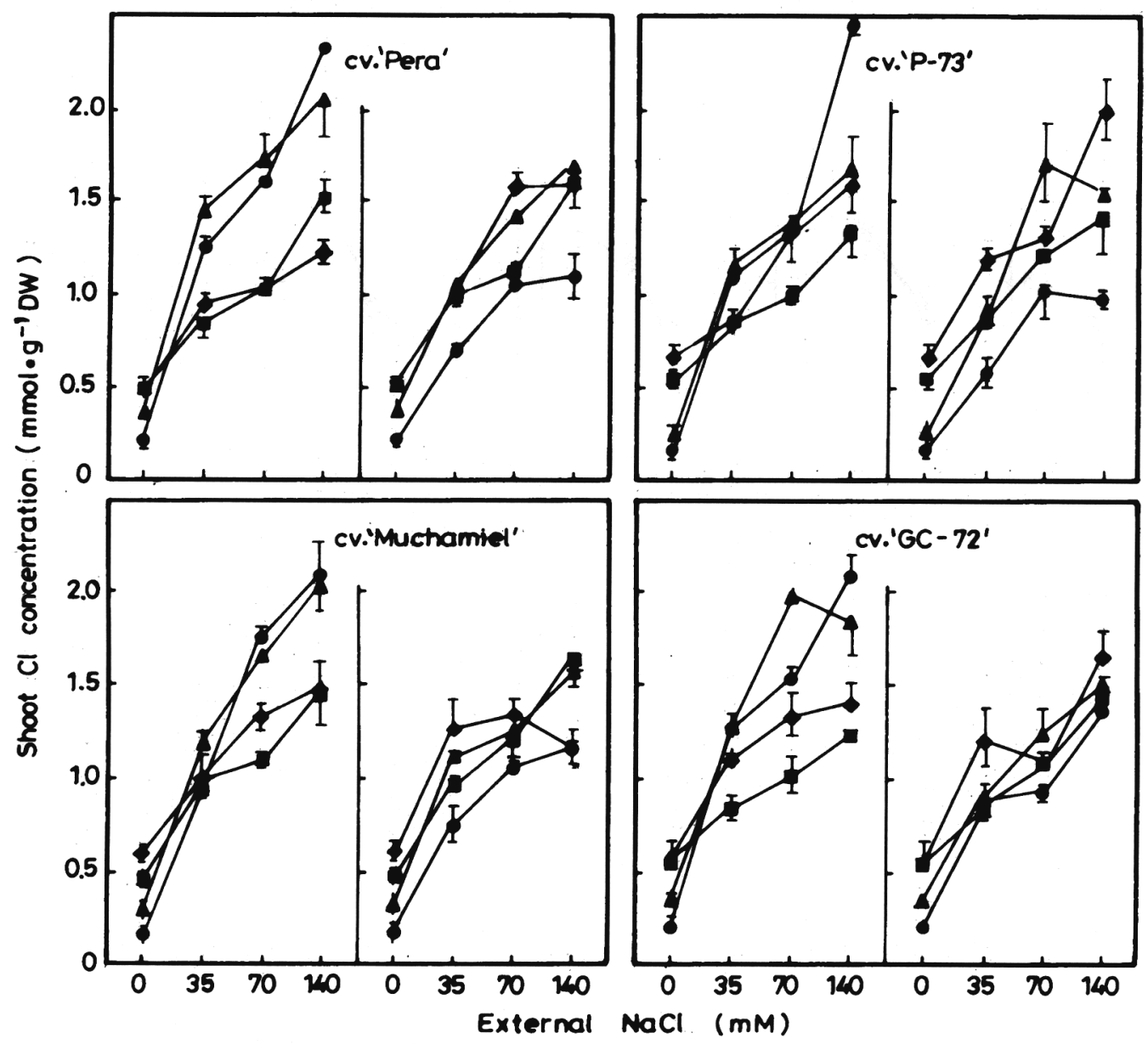

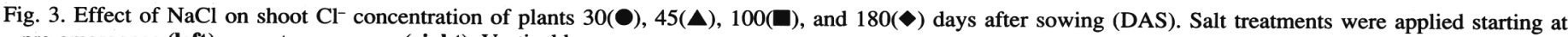
pre-emergence (left) or post-emergence (right). Vertical bars represent SE. 
observed with Cl-. The highest $\mathrm{Na}^{+}$concentrations with increased salinity were found in 45-day-old seedlings, followedby 30-day-old seedlings. No great differences were found between 100- and 180-day-old plants, although the concentration tended to be lower in loo-day-old plants.

Shoot $\mathrm{K}^{+}$concentrations in control plants decreased with plant age, except for 45-day-old seedlings, which had the highest $\mathrm{K}^{+}$ concentrations. These seedlings also decreased in $\mathrm{K}^{+}$the most in saline medium compared with the control when salt was applied pre-E or post-E (Fig. 5). In most genotypes, $\mathrm{K}^{+}$concentrations in mature plants decreased as salinity increased, although these decreases were much lower than in 45-day-old seedlings. Changes in shoot $\mathrm{K}^{+}$concentrations with increased salinity were not noted in the 30-day-old seedlings of most genotypes.

\section{Discussion}

The effect of salinity on plants was expressed as reduced shoot DW because the vegetative growth is the most widely used index in studies on salt tolerance in tomato (Cruz et al., 1990). When salt was applied pre-E, the salt tolerances of tomato genotypes generally increased with plant age in a manner similar to responses observed in barley (Hordeum spp.), corn (Zea mays L.) rice (Oriza sativa L.), and wheat (Triticum spp.) (Maas, 1986). However, when salt was applied post-E, the tolerances were greater at the early, rather than at the advanced, growth stage. It is evident from our data that the different salt tolerances shown by these genotypes cannot be ascribed to plant age, since, at day 45 , the degree of salt tolerance would have been different depending on salt application time. At pre-E, the genotypes were salt sensitive, based on the marked decreases in shoot DW at various salt concentrations. At post-E, these genotypes were highly salt tolerant. However, the salt tolerance of mature genotypes was similar for both salt application times, a result that suggests that plants require a period of adaptation to salinity. Consequently, when different methods are used to determine plant responses to salinity, results can be compared only if salinity effects are determined on mature plants or if the salt application time is sufficiently long for the plants to develop mechanisms to adapt to salinity. This adaptive response is observed when plants are exposed to a nonlethal $\mathrm{NaCl}$ concentration for longer than a critical time period. When assessed by vegetative growth, the adaptive response has been similar in pre-Eand post-E-treated plants. However, yields of these genotypes increased when salt was applied pre-E, especially at higher salt concentrations. This response could be due to the longer period of adaptation to salinity for plants treated pre-E. This effect is not evident in shoot DW, possibly due to the more severe effect of salinity on fruit development than on shoot growth (Papadopoulos and Rendig, 1983).

Easily measured characteristics are particularly useful for screening procedures, but they must correlate with fruit yield. Pasternak et al. (1979) found a high positive correlationbetween tomato yield and size of 45-day-old plants in seven varieties grown under salt stress. In the present study, a linear relationship also has been

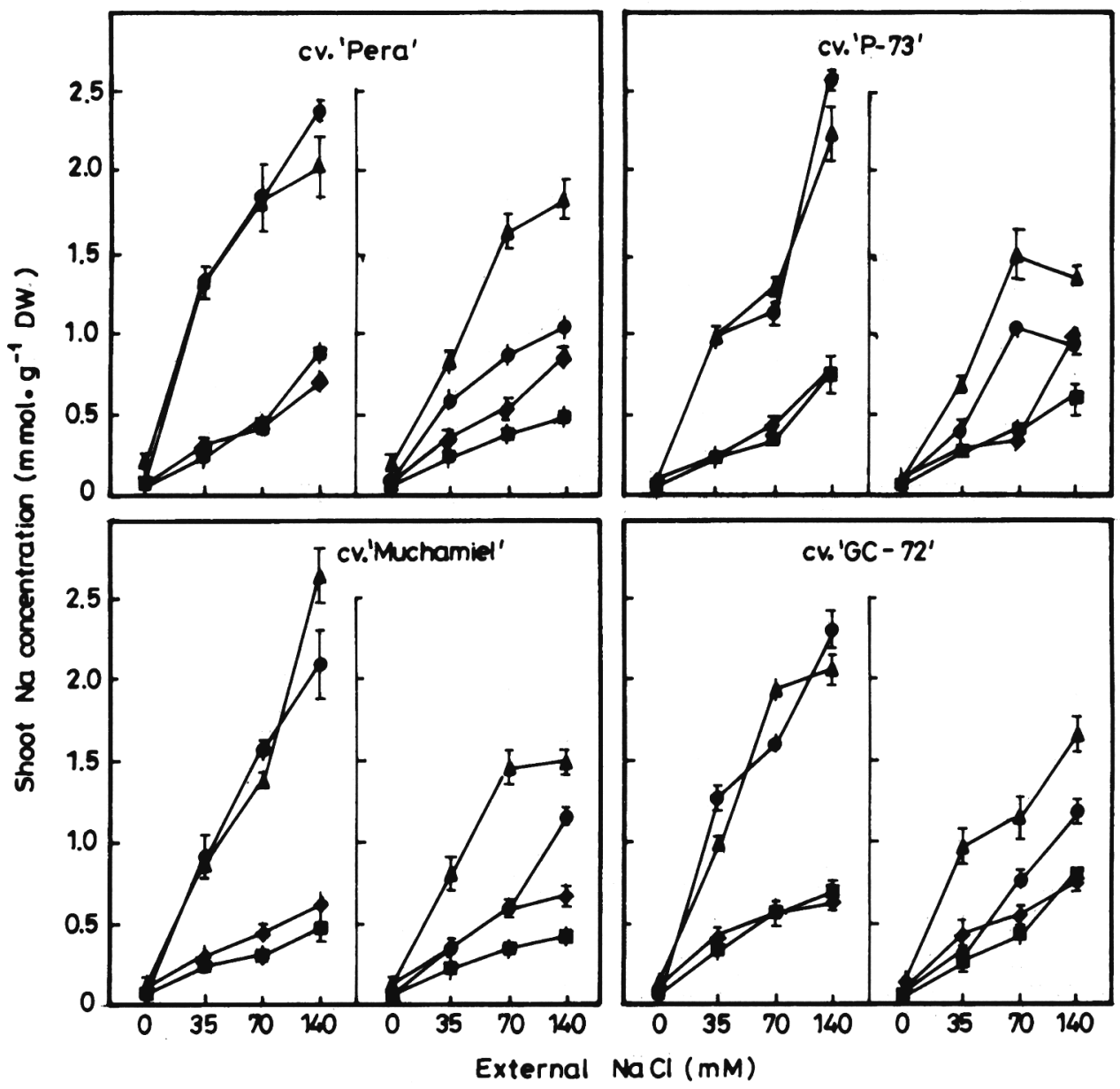

Fig. 4. Effect of $\mathrm{NaCl}$ on shoot $\mathrm{Na}^{+}$concentration of plants $30(\mathbf{}), 45(\mathbf{\Delta}), 100(\square)$, and $180(\diamond)$ days after sowing (DAS). Salt treatments were applied starting at pre-emergence (left) or post-emergence (right). Vertical bars represent SE. 


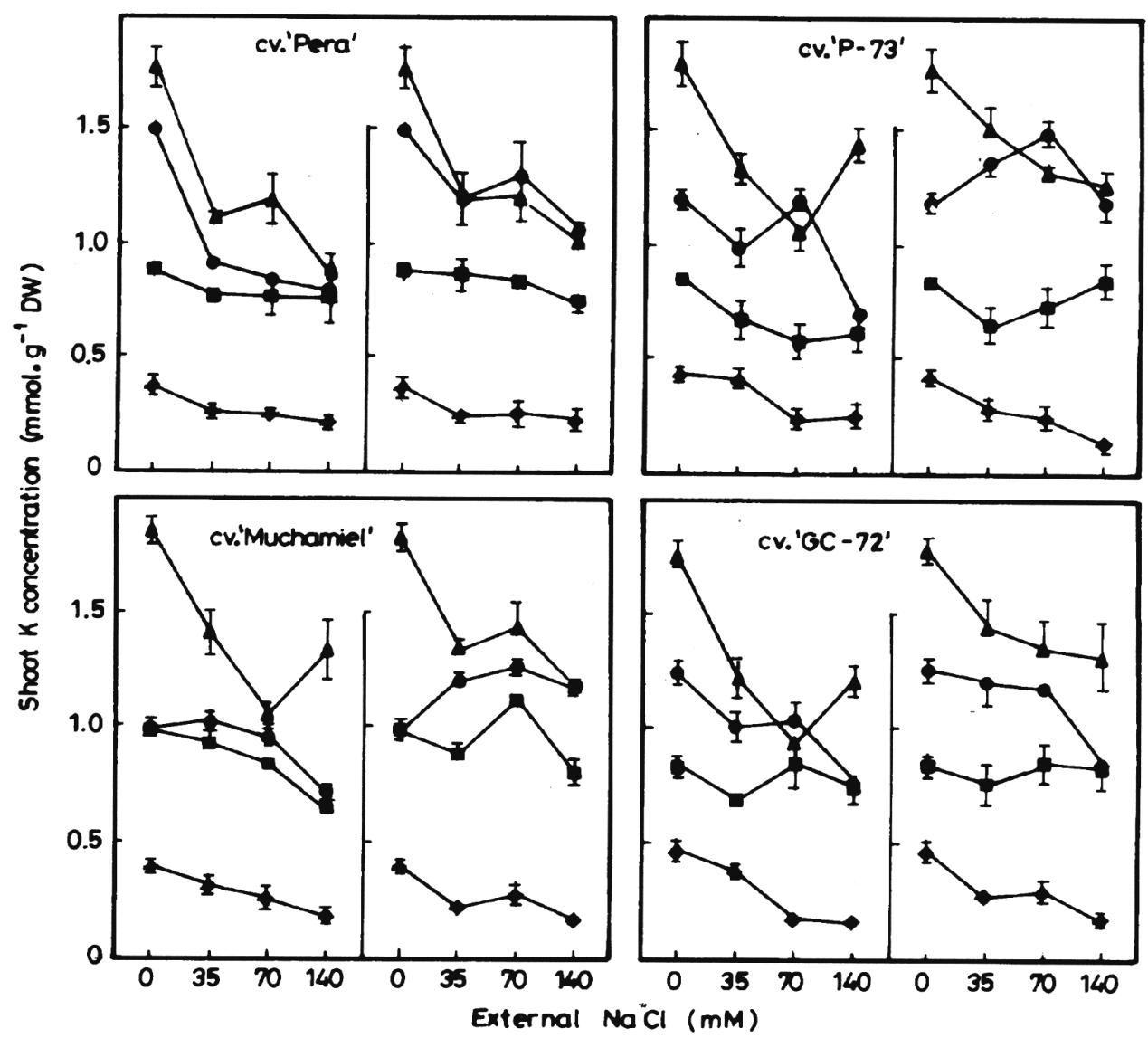

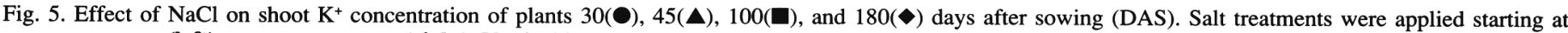
pre-emergence (left) or post-emergence (right). Vertical bars represent SE.

found between fruit yield and shoot DW for all salt treatments applied pre-E or post-E, although the significance of the correlation coefficients varied with plant growth stage (Fig. 2). Differences in slopes, intercepts, or both in 30- and 45-day-old seedlings were due to differences in decreased plant shoot DW, depending on the salt application time. The fact that regression lines were not significantly different for both treatments in mature plants indicates that responses were similar in both cases.

Plants may adjust osmotically either by absorbing ions through roots and accumulating them in shoots or by synthesizing organic osmotica. In addition to osmotic shock, specific accumulation of $\mathrm{Cl}$ and $\mathrm{Na}$ ions in plants often is toxic and may be one of the main causes for growth inhibition under high salinity (Greenway and Munns, 1980; Yeo and Flowers, 1986). In this work, shoot DW decreased as shoot $\mathrm{Cl}$ - and $\mathrm{Na}^{+}$concentrations increased. The highest concentrations of both ions, mainly $\mathrm{Na}^{+}$, and the lowest shoot DW were found in 30- and 45-day-old plants treated pre-E. However, 45-day-old plants treated post-E were the most salt tolerant and had the highest $\mathrm{Na}^{+}$concentrations. Possibly, tomato plants become osmotically adjusted by absorbing ions through the roots while expending little energy, as has been reported by Zerbi et al. (1990). This explanation is supported by the work of Sánchez-Blanco et al. (1991). They reported that tomato plants grown under saline conditions were able to osmoregulate up to a certain limit, as leaf osmotic potential at full turgor first decreased and then was maintained during plant growth. Marschner (1986) reported that water deficit is the principal constraint in plants exposed to high salinity for short periods. However, in plants exposed for longer periods, in addition to water deficit, ion toxicity and imbalance limit plant growth.

When compared to control plants, 30- and 45-day-old plants treated pre-E had much higher $\mathrm{Cl}$ - and $\mathrm{Na}^{+}$concentrations than those treated post-E. However, in both cases, $\mathrm{Cl}$ and $\mathrm{Na}$ ion concentrations in mature plants were similar, as were the shoot DWs of these plants. This fact suggests that the ability to grow under high salinity depends on the presence or efficiency of mechanisms to adjust internal salt concentrations.

\section{Literature Cited}

Ashraf, M. and T. McNeilly. 1988. Variability in salt tolerance of nine spring wheat cultivars. J. Agron. Crop Sci. 160:14-21.

Bolarín, M.C., F.G. Fernández, V. Cruz, and J. Cuartero. 1991. Salinity tolerance in four wild tomato species using vegetative yield-salinity response curves. J. Amer. Soc. Hort. Sci. 116:286-290.

Caro, M., V. Cruz, J. Cuartero, M.T. Estañ, and M.C. Bolarín. 1991. Salinity tolerance of normal-fruited and cherry tomato cultivars. Plant \& Soil 136:249-255.

Cruz, V., J. Cuartero, M.C. Bolarìn, and M. Romero. 1990. Evaluation of characters for ascertaining salt stress responses in Lycopersicon species. J. Amer. Soc. Hort. Sci. 115:1000-1003.

Greenway, H. and R. Munns. 1980. Mechanisms of salt tolerance in nonhalophytes. Annu. Rev. Plant Physiol. 31:149-190.

Guerrier, G. 1984. Selectivité de fixation du sodium au niveau des embryons et des jeunes plantes sensible ou tolerante au NaCl. Can. J. Bot. 62:1791-1798. 
Hoagland, D.R. and D.I. Arnon. 1950. The water-culture method for growing plants without soil. Calif. Agr. Expt. Sta. Circ. 347.

Hunt, R. 1982. Plant growth curves. An introduction to the functional approach to plant growth analysis. Edward Arnold, London.

Jones, R.A. 1986. High salt tolerance potential in Lycopersicon species during germination. Euphytica 35:575-582.

Kingsbury, R.W. and E. Epstein. 1984. Selection for salt resistant spring wheat. Crop Sci. 24:310-315.

Maas, E.V. 1986. Salt tolerance of plants. Applied Agr. Res. 1:12-26.

Marschner, H. 1986. Mineral nutrition in higher plants. Academic, London.

Norlyn, J.D. and E. Epstein. 1984. Variability in salt tolerance of four triticale lines at germination and emergence. Crop. Sci. 24: 1090-1092.

Papadopoulos, I. and V.V. Rendig. 1983. Tomato plant response to soil salinity. Agron. J. 75:696-700.

Pasternak, D., M. Twersky, and Y. DeMallach. 1979. Salt resistance in agricultural crops. In: H. Mussel1 and R.C. Staples (eds.). Stress physiology in crop plants. Wiley, New York.

Sánchez-Blanco, M.J., M.C. Bolarìn, J.J. Alarcón, and A. Torrecillas. 1991. Salinity effects on water relations in Lycopersicon esculentum and L. pennellii. Physiol. Plant. 83:269-274.

Shannon, M.C. 1985. Principles and strategies in breeding for higher salt tolerance. Plant \& Soil 89:227-241.

Shannon, M.C., J.W. Gronwald, and M. Tal. 1987. Effects of salinity on growth and accumulation of organic and inorganic ions in cultivated and wild tomato species. J. Amer. Soc. Hort. Sci. 112:416-423.

Yeo, A.R. and T.J. Plowers. 1986. Salinity resistance in rice (Oriza sativa, L.) and a pyramiding approach to breeding varieties for saline soils. Austral. J. Plant Physiol. 13:161-173.

Zerbi, G., D.R. Lecain, and J.A. Morgan. 1990. Concurrent action of salinity and water stress on leaf gas exchange and water relations in tomato. J. Hort. Sci. 65:675-681. 